\title{
'It Feels Like I Am Weighed Down By Societal Demands': A Mixed Method Study of Gender Norm Attitudes and Psychological Wellbeing in a Sample of Nigerian Youths
}

\author{
Amarachi, M. Ogueji, \\ Department of Sociology, University of Ibadan, Nigeria \\ Jun, K. Ng, \\ Department of Educational Psychology and Counselling, \\ University of Malaya, Malaysia \\ Ifeanyichukwu, A. Ogueji, \\ Department of Psychology, University of Ibadan, Nigeria
}

Doi:10.19044/esj.2020.v16n5p145 ～URL:http://dx.doi.org/10.19044/esj.2020.v16n5p145

\begin{abstract}
The association between gender norm attitudes and psychological wellbeing (PWB) has been a major area of gender and health studies that is observed to be scanty in African literature, with the few related studies that exist often adopting quantitative methods only. Thus, to expand the methodology and findings of these few existing related studies, a mixed method research was used to study the association between gender norm attitudes outcomes (egalitarian \& traditional) and PWB in a sample of Nigerian youths selected from the six (6) geopolitical zones of Nigeria. The total participants (i.e. quantitative plus qualitative study) were 303 purposively sampled youths, who were members of the National Youth Service Corps (NYSC). The mean age $=25.52$ years $(\mathrm{SD}=3.02)$ for quantitative study participants, and mean age $=27.2$ years $(\mathrm{SD}=3.01)$ for qualitative study participants. Data were collected using standardized questionnaires and indepth interviews. Conclusively, it was drawn from the findings that, although traditional gender norms seemed to enhance PWB more than egalitarian gender norms in the qualitative study, surprisingly there were some adverse effects of traditional gender norms which participants may be unaware of that was affecting their PWB as revealed in the quantitative study. Interventions that promotes gender equality should be embarked on.
\end{abstract}

Keywords: Gender Norm Attitudes (Traditional \& Egalitarian), Psychological Wellbeing (PWB), Youths 


\section{Introduction}

Gender norm attitudes which has two major outcomes, i.e. egalitarian or traditional beliefs, plays a very key role in the wellbeing of persons in the society. Meaning that attitudes towards what is expected of a person as been male or female could account for a significant amount of a person's normal functioning. Thus, the importance of this present study. This study is interested in exploring the differences in psychological wellbeing between youths that uphold egalitarian or traditional beliefs, using a mixed method design. Psychological wellbeing is a state of wellness, characterized by experience of self-determination and personal growth, the purpose and achievement of goals, the meaning in life, the actualization of personal capabilities and potentials, the commitment with the existential challenges and the selfrealization (Ryan \& Huta, 2009). Egalitarian beliefs uphold equality across genders, whereas traditional beliefs uphold a gender as superior over others (Geeta, 2011).

In African literature, studies have attempted to understand the wellbeing of males and females with much neglect to the contributions of gender norm attitudes. For instance in a sample of Nigerian youths $(16-33$ years of age), Sydney-Agbor, Ebeh and Onyeanu (2018) showed that there was no significant gender difference in mental wellbeing. Likewise in a sample of South African youths, Roothman, Kirsten and Wissing (2003), found that on the dimensions of the measures of wellbeing, males scored higher on physical self-concept, automatic thoughts (positive), constructive thinking, cognitive flexibility, total self-concept, and fortitude. On the other hand, females scored higher on the expression of affect, somatic symptoms, and religious well-being. Whereas, no significant gender difference was found on sense of coherence, satisfaction with life, affect balance, emotional intelligence, self-efficacy, and the social components of self-concept and of fortitude. Also, Anyanwu (2011) in a Nigerian study pointed that further exploration of the influence of gender and culture on the psychological wellbeing of youths should be looked into.

Furthermore, the very few African studies that have associated gender norm attitudes and wellbeing have reflected the importance for further studies on this topic with the use of advanced research designs that expands findings from previous studies. In a cross-cultural study, involving male college students from Kenya and the United States of America (USA), Mahalik, Lagan, and Morrison (2006), found that conforming to traditional ideals of masculinity impacted the psychological health behaviors of men. Furthermore, Labeodan (2005), reported that "despite strong likeness for western culture, male participants in that study showed some male egoistic traits, which were peculiar to Nigerian men in general, even for those living outside the country". This was linked to traditional gender norm attitudes upheld by these men, and 
an implication of this finding is that, women in that society seem to be at a disadvantage compared to their men counterparts. Hence, it is important to study how gender norm attitudes influences psychological wellbeing, with respect to this. In a post-disaster survey, Onuoha and Bada (2016) reported that females showed higher psychological wellbeing than male counterparts, and this was strongly attributed to the common practice in many Nigerian communities that encourages a favorable and tender treatment of distressed females over males. Furthermore, the Nigeria Men and Gender Equality Survey (NiMAGES, 2015) found in a survey that traditional perspectives of gender norms acts as glass ceiling effects in the Nigerian society, and this could be harmful to the development of both males and females in the Nigerian society. Thus, diminishing the wellbeing and quality of life of persons. Staveren and Odebode (2007) reported that the Yoruba society in Nigeria is affiliated with gender inequality and this poses unpleasant effects on the functioning and wellbeing of persons in that society.

In a study that expanded the influence of gender norms and other social factors on health outcomes, Ugwu and Kok (2015) found that gender norms do not only influence psychological wellbeing but also reproductive health outcomes. These findings showed that the harmful outcomes of reproductive health was initiated by the "harsh" gender norms over "soft" gender norms. Thus, gender norms may be doing more harm than good where it is wrongly enforced. Furthermore, Eneh and Nkamnebe (2011) found that patterns of gender inequality in Nigeria influences the socioeconomic status of males and females, and this might have been accounted for by certain gender norms that are practiced within the Nigerian society. Also, the study ascertained that these may limit the quality of life and wellbeing of both males and females in the Nigerian context.

Beyond Africa, Shek and Liang (2018) in a longitudinal study conducted in Hong Kong found that gender norms was significantly associated with psychological wellbeing in a sample of Chinese youths. However, the gendered feature accounting for differences in wellbeing was not obvious. Matud, Lopez-Curbelo and Fortes (2019) in a sample of Spanish adults found that adherence to traditional gender norms predicted the psychological wellbeing of men and women, with both men and women having masculineinstrumental and feminine-expressive showing the greater wellbeing. These findings suggested that advanced studies are required to test the causal links between variables examined in the study (Matud, Lopez-Curbelo \& Fortes, 2019). Furthermore, Fleming and Agnew-Brune (2015) reported that, gender norms, psychological wellbeing and health behaviors are varied depending on the society, thus understanding of the associations among gender norms, psychological wellbeing, and health outcomes across cultures appears imperative for a meaningful policy action in the area of gender equality. In 
very previous times, literature has shown that gender norm attitudes was also a determinant of psychological adjustment, thus showing consistencies with current findings. For instance Grimmell and Stern (1992) found in a sample of European Psychology students that gender norms contributes to a less report of psychological wellbeing, with both males and females being confused about the nature of standard behaviors and demands of real life situations. Similarly, Blazina and Watkins (1996) found in a study that gender norms was predictive of psychological wellbeing, and other behaviors such as psychological helpseeking behaviors.

Kaya, Iwamoto, Brady, Clinton and Grivel (2018) also determined in a study that, both masculine norm conformity and gender role conflicts were significantly associated with increased and decreased wellbeing among young adult men. Hori (2010) in a cross-national study found that, gender norms was a predictor of psychological wellbeing, with stressful gender norms showing adverse effects on the psychological wellbeing of study participants. In a British sample, Brown and Roberts (2014) found that participants that upheld traditional beliefs over egalitarian beliefs reported less wellbeing, with suggestions for further studies on this emphasized. Ellemers (2018) reported in a study that gender norms determined the way males and females attended to and conducted themselves and others around them, with this having impacts on their wellbeing and social relationships. Thus, rigid gender norms may have negative impacts on the wellbeing and social relationships of both males and females. In addition, Kagesten, Gibbs, Blum, Moreau, Chandra-Mouli, Herbert and Amin (2016) found that in a sample of adolescents, gender norm attitudes develop from childhood resulting from early socialization processes, and this is impactful to their social relationship formation, goal setting and health behaviors.

Nigeria is a very traditional society, although the country has embraced modernization, majority of its members still uphold their cultural beliefs in high esteem. Thus, it is important to understand that the family setting as an institution is the first place an individual comes in contact with before the outer world and this could be a powerful tool for inculcating appropriate gender norm attitudes (Sa'ad, 2001). This institution has embedded in it strict gender norms. These norms are designed to guide members throughout their daily lives from the moment of conception to death, and deviation from them attracts strict penalties. In the typical Nigerian family, the men wields absolute control over their wives and other family members. This is visible in terms of child custody and property ownership. Women however bear the burden of unpaid house chores in which men do not share much, and these could pose certain limitations to the development of both males and females in the Nigerian society (NiMAGES, 2015). 
This study is particularly interested in youths because they can be used as change agents, such as change agents for harmful gender norms. Furthermore, a major weakness of the previous studies that have attempted to link gender norm attitudes and wellbeing was the methodology of those studies, because a quantitative approach was largely observed to have been the research designs often adopted in those studies (e.g. Roothman, Kirsten \& Wissing, 2003; Mahalik, Lagan, \& Morrison, 2006; Hori, 2010; Onuoha \& Bada, 2016; Kaya, Iwamoto, Brady, Clinton \& Grivel, 2018; Matud, LopezCurbelo \& Fortes, 2019). Thus, the desire to expand the methodology used in studying gender norm attitudes and psychological wellbeing is the premise upon which the present study adopted a mixed method research. The mixed method study strengthens the outcome of this study over previous similar studies. Also, literature supports the notion that a mixed method research is imperative for validating findings by drawing data from both quantitative and qualitative sources (Wisdom \& Creswell, 2013). As a result, the following research questions were raised:

1. What is the determinant role of gender norm attitudes on psychological wellbeing outcomes among youths in the qualitative study?

2. To what extent will gender norm attitudes determine psychological wellbeing outcomes among youths in the quantitative study?

\section{Research Hypothesis}

Related studies often found that societies where traditional gender norms were strongly practiced usually experienced low psychological wellbeing, and vice versa. Hence, this study hypothesized that:

Lower score (traditional beliefs) will be significantly associated with lower level of psychological wellbeing, whereas higher score (egalitarian beliefs) will be significantly associated with higher level of psychological wellbeing.

\section{Theoretical Framework}

\section{The Social Role Theory}

The social role theory of Eagly (1987) was one of the theories used in providing theoretical explanations for this study. The key ideas about this theory is that the differences and similarities of men and women emerge due to the social role they occupy. Fundamentally, the pattern is that women take up more domestic task which could be paid or unpaid and they are generally in low status occupations. On the other hand, men occupy high paying jobs, they can easily go into politics and they are usually the breadwinners 


\section{The Stress Process Theory}

The stress process theory was developed by Pearlin (1989). This theory is composed of three components: stressors, mediators and health outcome. Pearlin argued that many of the stressful experiences that an individual faces is caused by the surrounding social structures and people's location within them. Therefore those who come from disadvantaged social groups are very likely to face higher psychological problems.

\section{Theoretical Application}

The social roles that males and females occupy comes with a lot of expectations (gender norms). Persons who deviate from these roles usually experience sanctioning. For instance, those who occupy roles that are not conventional to their gender. Also, gender norms can be toxic for both males and females. Boys are mostly socialized to be tough and this form of upbringing can prevent them from seeking to express pains whenever they are distressed, which can eventually take a toll on their psychological wellbeing. Females on the other hand are more likely to seek for help and express themselves in painful situations, because they are socialized to be soft hearted. Beyond this, gender norm attitudes also can affect outcomes of social relationships within social structures in the society, and this could be sometimes harmful to the wellbeing of both males and females. For instance many women are often victims of wage gaps because of their lack of confidence to demand for wage increase and this could be imposed by certain gender norms. This could adversely affect the wellbeing of women in the workplace, unlike their male counterpart who are more likely to negotiate an increase in most given situations.

\section{Methods}

\section{Design}

This study adopted a mixed method research design. It comprised qualitative and quantitative research designs.

\section{Setting}

The quantitative and qualitative studies were carried out in the National Youth Service Corp (NYSC) secretariat selected in each of the six (6) geopolitical zones of Nigeria, which are: North West (NW), North East (NE), North Central (NC), South West (SW), South East (SE) and South South (SS). The NYSC is a compulsory service program that is organized by the Nigerian government to enable young graduates (not above 30 years old) offer community development services to the country and promote national unity. The justification for selecting the NYSC secretariat of each Nigerian geo- 
political zone as a research setting, is to enable the researchers access a large number of youths with diverse socio-cultural backgrounds.

\section{Participants}

Participants were selected using a purposive sampling method in each setting. In order to ensure equal number of selected participants from each setting, a total of 50 participants were sampled in each geopolitical zone for the quantitative study, and this gave a total of 300 participants. At the end, only 293 questionnaires were completed, and this gave a response rate of $97.70 \%$. For the qualitative study, a total of 10 participants were interviewed, with participants being selected from each geopolitical zone as well. Participants' mean age $=25.52$ years $(S D=3.02)$ for quantitative study, whereas mean age $=27.2$ years $(\mathrm{SD}=3.01)$ for qualitative study.

\section{Ethical Considerations}

Approval was sought from and granted by the local government inspector (s) of each setting who reviewed the research purpose and confirmed that the research brings no risks nor harm to participants. Informed consent was also obtained from participants. Also, the information of participants were kept strictly confidential and they were not coerced to make decisions during the point of presenting the research request. In case of further enquiries, the contacts of the authors were stated on the consent form.

\section{Instruments}

Standardized questionnaire was the instrument used in conducting the quantitative study, while for the qualitative study, in-depth interview was used to obtain responses from respondents, and the interview questions asked questions that associated gender norm attitudes with outcomes of psychological wellbeing. The interview questions were subjected to content validation before use.

The questionnaire for quantitative study obtained the demographic characteristics of respondents, it also assessed the gender norm attitudes with a scale adopted from the compendium of gender scales by Geeta (2011). In addition, it assessed the psychological wellbeing with a scale developed by Diener, Wirtz, Tov, Kim-Prieto, Choi, Oishi, and Biswas-Diener, (2009). Interpretation of the scales indicated that, high scores on the psychological wellbeing scale was translated as a strong psychological wellbeing and vice versa. In the gender norm attitudes scale, it indicated that high scores were translated as egalitarian beliefs, whereas low scores were translated as traditional beliefs. For the reliability coefficients in this study, 0.82 and 0.64 were obtained for the gender norm attitudes and psychological wellbeing scales respectively, using Cronbach's Alpha. 


\section{Procedure}

The first and third researchers together with trained research assistants approached the local government inspectors to explain the research purpose to them, and sought approval for data collection, and this was done in each setting. After approval was given, the researchers approached the youth corps members explaining the purpose of the study and seeking their consent to participate in the study. Those that voluntarily consented were administered the research instruments in collaboration with the research assistants and local government inspectors who were trained to assist in data collection. Respondents were not required to state any identifying information such as names, while responding to the research instruments, in order to enable them respond honestly. Also, if any participant had a need to quit the study, he or she was free to do so with no consequence. This was the same procedure for both quantitative and qualitative study, and it was replicated in all six (6) geopolitical zones where participants were recruited from. The interviews in the qualitative study lasted about 35 minutes per participant. The quantitative data were analyzed using SPSS (v. 22.0), whereas qualitative data were transcribed verbatim.

\section{Results}

Table I. Summary of the descriptive data showing the distribution of the study participants.

\begin{tabular}{|l|r|r|}
\hline & Freq. & \multicolumn{1}{l|}{ \% } \\
\hline Gender (Quantitative Study) & & \\
\hline Male & 160 & 54.6 \\
\hline Female & 133 & 45.4 \\
\hline Gender (Qualitative Study) & & \\
\hline Male & 5 & 50.0 \\
\hline Female & 5 & 50.0 \\
\hline Geopolitical Zone (Quantitative Study) & 31 & 10.6 \\
\hline North West (NW) & 24 & 8.2 \\
\hline North East (NE) & 80 & 27.3 \\
\hline North Central (NC) & 56 & 19.1 \\
\hline South West (SW) & 49 & 16.7 \\
\hline South East (SE) & 53 & 18.1 \\
\hline South South (SS) & & \\
\hline Geopolitical Zone (Qualitative Study) & 1 & 10.0 \\
\hline North West (NW) & 1 & 10.0 \\
\hline North East (NE) & 1 & 10.0 \\
\hline North Central (NC) & 2 & 20.0 \\
\hline South West (SW) & 3 & 30.0 \\
\hline South East (SE) & 2 & 20.0 \\
\hline South South (SS) & &
\end{tabular}


From the above table, of the total 293 participants in the quantitative study, $160(54.6 \%)$ were males and 133 (45.4\%) were females. The geopolitical zone distribution for the quantitative study, showed that 31 (10.6\%) were selected from North West (NW). 24 (8.2\%) were selected from North East (NE), 80 (27.3\%) were selected from North Central (NC), 56 $(19.1 \%)$ were selected from South West (SW), 49 (16.7\%) were selected from South East and $53(18.1 \%)$ were selected from South South (SS) areas of Nigeria.

In the qualitative study, a total of 10 participants ( 5 males, $50 \% ; 5$ females, $50 \%$ ) were interviewed. Furthermore, of the total 10 participants, 1 $(10 \%)$ was selected from North West (NW), 1 (10\%) was selected from North Central (NC), 2 (20\%) were selected from South West, 3 (30\%) were selected from South East Nigeria and 2 (20\%) were selected from South South (SS) areas of Nigeria.

\section{Hypothesis Testing Quantitative Phase}

The research hypothesis stated that, lower score (traditional beliefs) will be associated with lower level of psychological wellbeing, whereas higher score (egalitarian beliefs) will be associated with higher level of psychological wellbeing. This was tested using Pearson $r$, and presented in the table below.

Table II. Summary table of Pearson $r$ showing the association between gender norm attitudes (GNA) and psychological wellbeing (PWB) among participants.

\begin{tabular}{lll}
\hline & 1 & 2 \\
\hline 1 GNA & $\overline{0} .86^{* *}$ & \\
2 PWB & 1.46 & $2 \overline{8.92}$ \\
Mean & 0.28 & 14.82 \\
SD & $* * \mathrm{P}<0.01$ &
\end{tabular}

The above result is interpreted that there was a significant positive association between gender norm attitudes and psychological wellbeing $(\mathrm{r}=$ 0.86 ; $\mathrm{df}=291 ; \mathrm{P}<0.01)$. A positive association implied that participants that scored high on gender norm attitudes (egalitarian beliefs) also scored high on psychological wellbeing, whereas participants that scored low on gender norm attitudes (traditional beliefs) also scored low on psychological wellbeing. This significant association was taken further to determine the coefficient of determination $\left(r^{2}\right)$, i.e. $0.86^{2}=0.74$, thus the interpretation has it that, gender norm attitudes explained $74 \%$ variance of psychological wellbeing among participants, whereas the remaining $26 \%$ was explained by other variables not considered in this study. With these results, the stated hypothesis is accepted in this study. 


\section{Qualitative Phase}

The in-depth interview comprised questions that assessed the determinant role of gender norm attitudes on overall psychological wellbeing, and its dimensions (social relationships, meaning in life, self-acceptance, personal growth and development, autonomy and personal mastery of participants) among participants. Participants' responses were labelled using their age, gender and geopolitical zone from which they were selected from. Responses were transcribed verbatim, and the following themes emerged from the analyzed responses in the in-depth interview:

\section{Favorable attitudes towards traditional gender norms enhanced psychological wellbeing}

Participants in this category indicated in their responses that they were satisfied with the way their behaviors were in conformity with traditional gender norms, this made them feel good about themselves and their overall psychological wellbeing:

"I enjoy the life I live. Com'on, I am a youth pastor in my church, and I head my beautiful family. What more do I really want as a man?...These positions give meaning to my life (Age 28, Male, SE)"

"Hmmmm ...you asking if I lead a purposeful life regarding my gender? That's a very big question. Well, being a woman, together with my profession as a nurse constantly puts me in a position to nurture and care for others. This gives me fulfillment, and so yes, I lead a purposeful life (Age 30, Female, SW).

"Yeah, we all know it is a man's world...... As the only male child of my parents, due to limited resources, I was sent to school over my sisters. This makes my sisters, members of extended families and even my friends to have high regard for me (Age 24, Male, NE)'”.

"As a man, it will always be my duty to provide for my wife and daughters..... Being there for my family financially gives me joy, and allows me to not only meet their needs but also their overall life satisfaction (Age 30, Male, SE)"

\section{Favorable attitudes towards egalitarian gender norms enhanced psychological wellbeing}

Participants in this category indicated in their responses that they were satisfied with the way their gender behaviors were in conformity with 
egalitarian norms and this made them feel good about themselves and their overall psychological wellbeing:

"In terms of my gender norm and social relationship, I want to assume you mean my interaction with those around me" errrrm.... Let me say that in my family, anybody can take up any task irrespective of gender norms.......... For instance my father and my brothers cook a lot, therefore this allows us to be there for each other, thus strengthening my bond with each family members (Age 27, Female, SW)'”.

\section{Conformity to traditional gender norms was detrimental to psychological wellbeing}

Participants in this category indicated in their responses that they were distressed with the way their behaviors were in conformity with traditional gender norms and for fear of sanctioning, they lacked confidence to go against the norms that are traditionally associated with their genders:

"In my place of work, whenever there is an official meeting and it's time for refreshment my boss always insist I serve my other colleagues........You know what?, I guess it's because I'm the only female at work. I don't feel comfortable doing this but I have no choice I mean, his my boss (Age 25, Female, SS).

"This is exemplified in raising our kids in my family. Taking care of my kids gives me joy............ But at times, it can be very stressful. I really wish my husband could help out. Whenever I ask him to, he makes it clear that it is his job to provide for me and the kids while it is solely mine to look after the kids(Age 29, Female, NC)".

"I got married while in the university. I told my husband I won't be having children until I was done with school. Although my husband was fine with my decision, his family members frowned at it, because they felt I was deviating from my gender role.... This gave me a tough time in the early years of my marriage (Age 30, female, SS)".

Any time my wife is unavailable to go to the market, I handle this task for the household...... At the market, many sellers always ask why my wife is not doing the shopping herself. I do not have a problem handling this task but at times the unsolicited advice of why my wife should be doing this gets to me (Age 28, male, NW)", 
"Cooking is an activity I enjoy doing. Actually, I hope to become a chef in the next 5 years here in Nigeria...... But my greatest fear is that in this part of the world females are the ones recognized in this field...... This gets me worried about my prospect (Age 21, male, SE)".

\section{Discussion and Recommendation}

This study contributed differently to knowledge by adopting a mixed research design to test the associative role of gender norm attitudes with psychological wellbeing in a sample of Nigerian youths selected from the six (6) geopolitical zones of Nigeria. The qualitative phase of this study showed that participants reported that traditional gender norm attitudes was enhancing psychological wellbeing among them. In addition, findings showed that participants that deviated from the norms associated with their gender due to the egalitarian beliefs that they upheld, were often frowned at, also findings showed that some participants felt pressured to conform to traditional gender norms and this adversely affected their psychological wellbeing.

On the other hand, the quantitative study showed that traditional beliefs was significantly associated with lower level of psychological wellbeing, while egalitarian beliefs was significantly associated with higher level of psychological wellbeing. These findings contrasted findings in the qualitative study which showed that some participants reported to be satisfied about the way traditional gender norms determines their behaviors within their societies. Thus, this implies that although participants seem fulfilled with the determinant role of traditional gender norm attitudes on their behaviors, these traditional gender norm attitudes in a way is adversely affecting the overall psychological wellbeing of participants with or without participants knowing about it as shown by the quantitative results. However, results from both qualitative and quantitative studies were similar in that both studies reflected that conforming to traditional gender norms was detrimental to the psychological wellbeing of participants.

Possible explanations for the findings in this study may be that the Nigerian society assigns traditional norms to be associated with males and females, thus expecting males to hide their pains rather than seek expression of pain whenever they are pained or stressed out. On the other hand, while it is uneasy for males to express pain, it is easy for females to express their states of stress whenever they feel stressed out because of traditional gender norms that expects men to be tough and domineering, while women should be tender and nurturing. This also implies that a man may be undergoing stress posed by his gender norms but for fear of being sanctioned by the society, he may choose to conceal it rather than seek help or support. This could also affect the help-seeking behaviors of men when they are distressed and this is supported 
by previous studies that found that gender norm attitudes does not only determine psychological wellbeing, but also psychological help-seeking behaviors (e.g. Blazina \& Watkins, 1996).

These findings have implications for gender role and stress theories, by confirming the applicability of the core assumptions of Eagly (1987) and Pearlin (1989) to the sample of Nigerian youths in this study. Beyond theoretical implications, the findings from this study are also in consonance with previous findings that have found that gender norm attitudes determines our behaviors, and this is impactful on our wellbeing and social relationships (e.g. NiMAGES, 2015; Mahalik, Lagan, \& Morrison, 2006; Roothman, Kirsten \& Wissing, 2003; Staveren \& Odebode, 2007; Hori, 2010; Brown \& Roberts, 2014; Ugwu \& Kok, 2015; Ellemers, 2018). In addition, the findings from this study also implies that due to gender norms, both male and females may be confused about appropriate behaviors, and this threatens their wellbeing as similarly found in a very previous study (e.g. Grimmell \& Stern, 1992). On the other hand, the findings from this study that traditional gender norms was associated with lower level of psychological wellbeing, contradicted findings from previous studies that showed that features of traditional gender norms (e.g. masculine-instrumental \& feminine-expressive) promotes psychological wellbeing, and this contradiction may be explained by environmental differences in these studies (e.g. Matud, Lopez-Curbelo \& Fortes, 2019; Kaya, Iwamoto, Brady, Clinton \& Grivel, 2018).

With these findings, it is recommended that a thorough education at grassroots levels that enlightens people on the adverse effects of strictly enforcing gender norms needs to be encouraged. This is supported by the findings in this study. Also, it is recommended that programs that advocates for gender equality should be strongly incorporated in places where youths are often involved in a lot of activities, such as the school, religious centers or in the case of Nigeria, the NYSC program. In the implementation of these recommendations, it is expected that the glass ceiling effects imposed by gender norms, as well as the adverse effects of gender norms will be reduced in the society.

\section{Strength and Weakness of Study}

This study cut across the total six (6) geopolitical zones of Nigeria, by sampling participants with diverse socio-cultural backgrounds from each geopolitical zone, which is a strength of the study. Also, this study adopted a mixed method research design and made comparison of the findings obtained from both the quantitative and qualitative phase of the study, and this is another strength of the study. However, due to insufficient resources, this study limited the study participants to Nigerian youths, and further studies may fill up the gap on this weakness by adopting a cross-cultural approach. 


\section{Conclusion and Further Study}

Gender norm attitudes are very powerful societal and individual processes that are often neglected as determinants of wellbeing, especially in Africa where gender norms are often strictly enforced. Thus, it is hoped that this study adds to the very few studies that have been carried out to raise awareness on the predictive role of gender norm attitudes on health and wellbeing in Africa. Thus, apart from the influence of gender norm attitudes on psychological wellbeing, further studies may consider to uncover the associations between gender norm processes and other dimensions of human health.

\section{Authors' Contribution}

The first and second authors were responsible for the introduction and literature review. The third author was responsible for the methodology and quantitative phase. For the qualitative phase, the first and third authors were responsible. All authors were responsible for the discussion of findings and proofreading of the final manuscript.

\section{Acknowledgement}

The various local government inspectors of each setting where data were collected are acknowledged for their assistance which aided the approval and data collection process of this study. Finally, the Communication for Change (C-Change), Fhi360 and the United States Agency for International Development (USAID) are acknowledged for supporting the development of the compendium of gender scales by Geeta (2011), which was adopted in this study.

\section{References:}

1. Anyanwu, J. I. (2011). Parental relationship as a correlate of psychological wellbeing of southeastern Nigerian adolescents. African Journal of Teacher Education, 1(1), 195-208

2. Blazina, C., \& Watkins Jr, C. E. (1996). Masculine gender role conflict: Effects on college men's psychological well-being, chemical substance usage, and attitudes towards help-seeking. Journal of Counseling Psychology, 43(4), 461.

3. Brown, H., \& Roberts, J. (2014). Gender role identity, breadwinner status and psychological well-being in the household. Sheffield Economic Research Paper Series.

4. Diener, E., Wirtz, D., Tov, W., Kim-Prieto, C., Choi, D., Oishi, S., \& Biswas-Diener, R. (2009). 
5. New measures of well-being: Flourishing and Positive and Negative Feelings. Social Indicators Research 39: 247-266.

6. Eagly, A. H. (1987). Sex Differences in. Social Behavior: A SocialRole Interpretation.

7. Ellemers, N. (2018). Gender stereotypes. Annual review of psychology, 69, 275-298.

8. Eneh, O. C., \& Nkamnebe, A. D. (2011). Gender gap and sustainable human development in Nigeria: Issues and strategic choices. Asian J. Rural Dev, 1(1), 41-53.

9. Fleming, P. J., \& Agnew-Brune, C. (2015). Current trends in the study of gender norms and health behaviors. Current opinion in psychology, 5, 72-77.

10. Geeta, N., (2011). Compendium of Gender Scales. Washington, DC: FHI 360/C-Change

11. Grimmell, D., \& Stern, G. S. (1992). The relationship between gender role ideals and psychological well-being. Sex Roles, 27(9-10), 487497.

12. Huta, V., \& Ryan, R. M. (2010). Pursuing pleasure or virtue: The differential and overlapping well-being benefits of hedonic and eudaimonic motives. Journal of happiness studies, 11(6), 735-762.

13. Hori, M. (2010). Gender differences and cultural contexts: psychological well-being in cross-national perspective. LSU Doctoral Dissertation, 3324

14. Kågesten, A., Gibbs, S., Blum, R. W., Moreau, C., Chandra-Mouli, V., Herbert, A., \& Amin, A. (2016). Understanding factors that shape gender attitudes in early adolescence globally: A mixed-methods systematic review. PloS one, 11(6), e0157805.

15. Kaya, A., Iwamoto, D. K., Brady, J., Clinton, L., \& Grivel, M. (2018). The role of masculine norms and gender role conflict on prospective wellbeing among men. Psychology of Men \& Masculinities 20(1), 142147.

16. Labeodan, M. O. (2005). The family lifestyle in Nigeria. A dissertation submitted to the School of Statistics an Actuarial Science, University of the Witwatersrand, Johannesburg, South Africa.

17. Mahalik, J. R., Lagan, H. D., \& Morrison, J. A. (2006). Health behaviors and masculinity in Kenyan and US male college students. Psychology of men \& Masculinity, 7(4), 191.

18. Matud, M. P., López-Curbelo, M., \& Fortes, D. (2019). Gender and Psychological Well-Being. International journal of environmental research and public health, 16(19), 3531.

19. Nigerian Men and Gender Equality Survey (NiMAGES) (2015). Available at http://www.v4c-nigeria.com/download/1419/ 
20. Onuoha, U. C., \& Bada, O. V. (2016). Spirituality, Self-efficacy, Age, and Gender as predictors of Psychological Wellbeing among Flood Survivors in Nigeria. Journal of Humanities and Social Science 21 (10), 43-49.

21. Pearlin, L. I. (1989). The sociological study of stress. Journal of health and social behavior, 241-256.

22. Roothman, B., Kirsten, D. K., \& Wissing, M. P. (2003). Gender differences in aspects of psychological well-being. South African journal of psychology, 33(4), 212-218.

23. Sa'ad, A. M. (2001). Traditional institutions and the violation of women's human rights in Africa: The Nigerian case. African Women and Children. Crisis and Response.

24. Shek, D. T., \& Liang, L. Y. (2018). Psychosocial factors influencing individual well-being in Chinese adolescents in Hong Kong: A sixyear longitudinal study. Applied research in quality of life, 13(3), 561584.

25. Staveren, I. V., \& Ode bode, O. (2007). Gender norms as asymmetric institutions: A case study of Yoruba women in Nigeria. Journal of Economic Issues, 41(4), 903-925.

26. Sydney-Agbor, N., Ebeh, R., \& Onyeanu, M. (2018). Predictors of mental wellbeing among undergraduates in Eastern Nigeria. African Journal of Social and Behavioural Sciences, 8(2).

27. Ugwu, N. U., \& de Kok, B. (2015). Socio-cultural factors, gender roles and religious ideologies contributing to Caesarian-section refusal in Nigeria. Reproductive health, 12(1), 70.

28. Wisdom, J., \& Creswell, J. W. (2013). Mixed methods: integrating quantitative and qualitative data collection and analysis while studying patient-centered medical home models. Rockville: Agency for Healthcare Research and Quality. February 2013. AHRQ Publication No. 13-0028-EF. 